\title{
A DTMEs-Based Digital Twin System Construction Method For Smart Factory
}

Luyao Xia ( $\sim$ luyao.x@tongji.edu.cn )

Tongji University

Lu Jianfeng

Enterprise Digital Technology and Engineering Research Center of the Ministry of Education

Hao Zhang

Tongji University

Mengying Xu

Tongji University

Zhaojia Li

Tongji University

Sheng Wang

Tongji University

\section{Research Article}

Keywords: Digital twin, Full life cycle, DTMEs, Smart factory DTS

Posted Date: July 19th, 2021

DOl: https://doi.org/10.21203/rs.3.rs-633211/v1

License: (c) (i) This work is licensed under a Creative Commons Attribution 4.0 International License.

Read Full License 


\title{
A DTMEs-based digital twin system construction method for smart factory
}

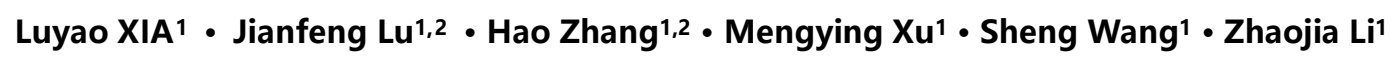

\begin{abstract}
Many enterprises have built their own digital twin factory model for physical factory planning, simulation optimization and real-time monitoring. However, the digital twin system, which has a single field, a short time cycle and unsinkable service, cannot fully reflect the interaction and integration of the physical and information world required by intelligent manufacturing. Therefore, the research on the construction method of the smart factory digital twin system with cross-domain and multi-model has an important influence on the application of smart manufacturing. In view of the above problems, this paper proposes the concept and composition of digital twin manufacturing ecosystem (DTMEs) based on the requirements and characteristics of product lifecycle, and analyzes the construction requirements of DTMEs for factory digital twin system, product digital twin system and supply chain digital twin system from the perspective of lifecycle. Finally, the smart factory digital twin system architecture is applied to the digital and intelligent upgrading of the hydraulic cylinder factory. The experimental results show that the intelligent improvement of the hydraulic factory, the reduction of Work-in-process inventory and the advance of delivery time, and prove the feasibility and effectiveness of the smart factory digital twin system.
\end{abstract}

Keywords Digital twin $\cdot$ Full life cycle $\cdot$ DTMEs $\cdot$ Smart factory DTS

\section{Introduction}

With the development of economy and society, the core task of the manufacturing industry has shifted from the traditional model of expanding production scale to how to meet large-scale user customization, and how to provide users with individuation experience and better services. Therefore, manufacturing enterprises are under pressure to shorten delivery times, improve production efficiency, and reduce costs, and they need to respond quickly to the changing market [1]. In the new round of technological revolution and industrial reform, smart manufacturing has become the commanding heights and main directions for countries around the world to seize development opportunities, such as the "Strategy for American Leadership in Advanced Manufacturing" of the United States, the "industrial 4.0" of Germany, the "industrial 2050 strategy" of the UK and the "Made in China 2025" [2-3].

The key point for manufacturing enterprises to implement smart manufacturing is data and interconnection. Interconnection should not be limited to a certain area of manufacturing. It is

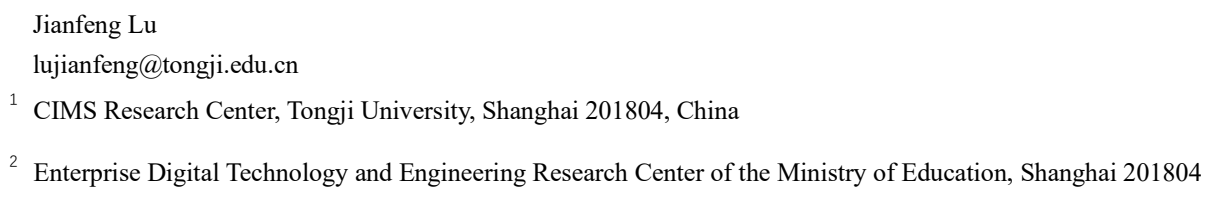


necessary to have the awareness of interconnection among the key elements in the manufacturing ecosystem. This sense of interconnection continues to prompt entrepreneurs and engineers to redefine the boundaries of the industry, and it is also a key process for the development of monomer intelligence to swarm intelligence. The smart factory is the key carrier for the realization of smart manufacturing, and it is also a multi-domain, multi-scientific integrated and interactive system. Compared with the traditional manufacturing process that relies on ERP/MES/MOM for production operation management, the smart factory gradually focuses on the in-depth integration of newgeneration information technologies such as the Internet of Things, cloud computing, and artificial intelligence with the life cycle of factory and product, which has the characteristics of selforganization, self-learning, self-decision-making, and self-adaptive to meet the development needs of smart manufacturing such as socialization, individualization, flexibility, servitization, and intelligence [4-7]. Therefore, the important issues that need to be paid attention to in the process of smart factory implementation are the virtual and real collaborative operation and efficient linkage of resource flow, information flow, and service flow in a multi-domain and multi-level smart manufacturing ecosystem [8]. In the smart manufacturing ecosystem, the virtual space highly virtualizes the resources of the physical space in a digital way, and intelligently controls and optimizes the physical space. At the same time, the physical space can efficiently feedback information to the virtual space and upgrade the virtual space.

Digital twin technology is to create virtual models of physical entities or processes by means of digitalization, and use data-driven virtual models to map the behaviors of physical entities or processes in the real environment in quasi real-time, and enhance the ability of physical entities by means of data and model fusion, intelligent decision-making, virtual-real interaction, etc. At the same time, digital twin is oriented by real-time, efficient and intelligent service, and fully integrates model, data and intelligent technologies to drive the efficient and smart operation of smart factory. Therefore, digital twin technology is the key enabling technology to realize smart factory [9-10]. In this context, Tao et al. proposed the concept and reference architecture of digital twin workshop, and studied the key problems such as heterogeneous elements fusion of physical workshop, multidimensional model fusion of virtual workshop, physical-cyber data fusion of workshop, and service / application fusion of workshop, which provided reference for enterprises to construct digital twin workshop [11-12]. Guo et al. proposed a workshop modeling framework based on digital twin, and conducted research and analysis on the problems such as product digital definition, resource modeling and digital definition of process information [13]. Zhao et al. proposed the method of combining value flow and digital twin technology to design factory that can meet the lean goal, and realized the iterative optimization design of the whole process through digital twin, and finally obtained the lean smart factory design scheme [14]. Park et al. proposed a digital twin-based CPS production system framework and applied it to micro-smart factory to reduce production time [15].

Park et al. also proposed the design and implementation architecture of digital twin in microfactory, and studied the support of digital twin for the design, operation and future decision-making 
of the factory lifecycle [16]. Tao et al. studied modeling and simulation, and dynamic prediction and evaluation of complex product lifecycle business process based on digital thread and digital twin [17]. Miao et al. analyzed the application of digital twin in typical scenarios of product development, manufacturing, maintenance and other stages of product lifecycle [18].

Although many scholars have carried out many studies on the concept and architecture of digital twin, and the introduction of digital twin system can effectively promote the collaboration and integration of physical space and cyber space in smart factory, but there are still problems in the construction of SFDTS:

(1) Smart factory is a system of multi-value intersection. At present, the construction of digital twin system mostly focuses on the workshop level or a certain stage of the manufacturing process, so there is a lack of research on the value interaction at the factory level in the entire product value chain;

(2) Smart factory is a multi-domain and continuous system, which contains the temporal-spatial intersection of resource flow, information flow and service flow. At present, few scholars study smart factory digital twin system from the perspective of multi-domain and factory/product lifecycle, so the smart factory digital twin system needs to be designed and constructed from the factory lifecycle, the product lifecycle, the supply chain, and solve the problem of interaction and integration among the three domains;

(3) Most researchers have emphasized the importance of virtual and real integration and intelligence of digital twin system, and clearly analyzed and designed the architecture of virtual and real factory integration of digital twin system. However, there is a lack of the research of digital twin combined with New IT technology to realize HCPS (human-cyber-physical system) in smart factory.

To solve the above problems, this paper proposes a method of constructing smart factory digital twin system (SFDTS) based on Digital Twin Manufacturing Ecosystem (DTMEs). The outline is organized as follows. Section 2 introduces the concept, characteristics and the digital twin lifecycle. Section 3 puts forward the concept and structure of DTMEs. Section 4 proposes the characteristics, architecture and evolution process of SFDTS. Section 5 gives a smart upgrade case of a hydraulic cylinder factory to verify the effectiveness and feasibility of the SFDTS.

\section{Digital Twin}

\subsection{The concept and characteristics of digital twin}

Michael Grieves proposed the concept of "virtual digital expression equivalent to physical products" in the Product Lifecycle Management (PLM) course of the University of Michigan in 2003 [19]. This concept was not called a digital twin until 2011, when Professor Michael Grieves proposed a digital twin model in his book on PLM [20], including physical entities, virtual entities, and connections between physical entities and virtual entities. At present, the digital twin model we adopt basically follow this three-dimensional model. Zhuang et al. proposed that digital twin is a process and method of using digital technology to describe and model the characteristics, behavior, 
formation process and performance of physical entities [21]. Digital twin is hyper-realistic virtual model corresponding to physical entity in the real world. With the research on the connotation description of the digital twin model and the practice of its implementation methods by domestic and foreign scholars, the connotation and characteristics of the digital twin are becoming more and more rich which are embodied as follows: (1) Everything can be expressed as twins. From the initial aircraft digital twin to the application of digital twin in various fields, physical entities in the real world can establish their corresponding digital twin in the virtual space; (2) The fractal description of digital twin has spatial hierarchical characteristics, i.e., digital twins describe physical objects in various fields from micro to macro level by level, and fractal description reflects the accuracy and comprehensiveness of physical objects described by digital twins; (3) Digital twin has the characteristic of time continuity. We construct digital twin from the perspective of the whole physical entity lifecycle. The digital twin in the previous stage will also continue to the next stage. Therefore, the digital twin is consistent throughout digital twin lifecycle [22-23].

\subsection{The description of digital twin lifecycle}

In fact, the fractal description and time continuity characteristics of digital twin mean that digital twin describe physical objects from two perspectives: object-oriented and process-oriented. Therefore, when we analyze the digital twin of physical objects lifecycle, we need to combine object-oriented and process-oriented digital twin. From the perspective of process-oriented, the digital twin inherits the information of the previous stage in every stage of digital twin lifecycle. From the object-oriented point of view, digital twin at each stage interacts with physical entity, and digital twins at different levels interact with each other. As another virtual "life body" of physical object in the physical object lifecycle, digital twin is endowed with specific functions at each stage of the whole physical object lifecycle.

According to the characteristics and functions of the digital twin, digital twin lifecycle is divided into three stages. The digital twin is another "life body" of the physical object, and the initial state of the "life body" is embryo, so the digital embryo stage is the early stage of the digital twin. Digital embryo is generated in the design stage of physical entity, and appears before physical entity. Therefore, using digital embryo to express the design intention of unrealized physical object is to define physical entity ideally and empirically. Digital embryo can be regarded as the virtual expression of physical entity after human brain has rationally and empirically recognized physical and functional attributes of physical entity, whose function is to simulate the physical entity with a virtual body. The digital mapping body stage is the mid-stage of digital twin, which is characterized by virtual-real mapping. Through multi-level digital mapping of physical entity, the virtual models of physical entity, behavior logic and operation process are established. Twin data is the basis of data-driven models, and the mapping relationship between physical entity and digital mapping body can be established based on twin data. Meanwhile, this mapping body will automatically evolve and upgrade according to real-time feedback of changes in physical entity. The twin intelligence stage 
is the final stage of the digital twin lifecycle, and it is also the stage when the digital twin has intelligence features. In this stage, the digital twin inherits the data and models of the previous two stages. With the help of big data mining and intelligent algorithms, it can accurately control the physical entity in the way of "knowledge model-smart decision-precise execution", so as to achieve the goal of "virtual control reality intelligently".

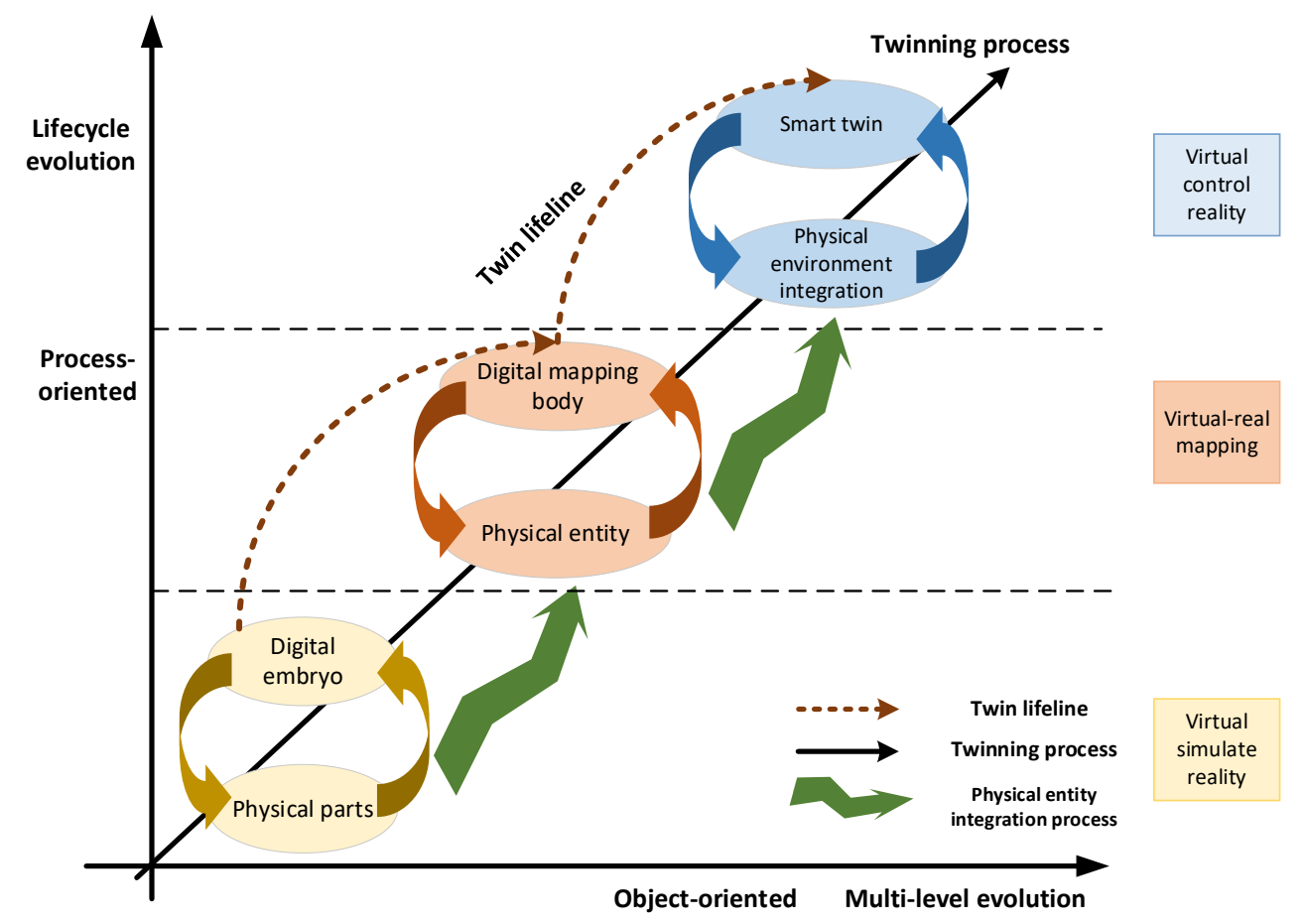

Figure 1 The evolution of digital twin

\section{Digital twin manufacturing ecosystem}

\subsection{The concept and composition of DTMEs}

The product manufacturing process is carried out in an extensive manufacturing system, which involves the collaborative and interactive operation of products and engineering design, management, production and other fields. The product field focuses on product modeling, simulation, quality management, and data governance from the perspective of the product lifecycle. The factory field focuses on the design, installation, operation and decommissioning of all production devices and their own system during the entire factory lifecycle. The business area is mainly concerned with supply chain management related to suppliers, customers and production activities. The smart factory is a place where manufacturing information flow, material flow, resource flow, etc. are intertwined and complicatedly related in the upstream and downstream areas of the above three fields, and it is also a meeting point that reflects the business links and data in various fields of manufacturing in real time. Therefore, the smart factory is the natural result of the development of the three fields of smart manufacturing system and the various elements of manufacturing in the space-time continuum.

It is a great challenge to integrate the three fields in the process of product manufacturing, each dimension in the manufacturing field needs to be integrated with other dimensions through digital 
thread. The tight integration and interaction within and between the three fields will lead to a shorter product development cycle, a more efficient supply chain, and a more flexible production system [24-25]. Therefore, from the perspective of the collaborative operation and optimized management process of various fields of the smart manufacturing system, the entire smart manufacturing system needs a virtual carrier to carry physical resource information and reflect the process of information interaction. The multi-level digital twin systems in various fields are constructed based on digital twin technology to build the Digital Twin Manufacturing Ecosystem (DTMEs), including factory DTS, product DTS, supply chain DTS, as shown in Figure 2. At the same time, SFDTS reconstructs and optimizes manufacturing units at different levels, and provides services for task requirements generated in different fields and stages of the smart manufacturing system. Its connotation has undergone extension and evolution.

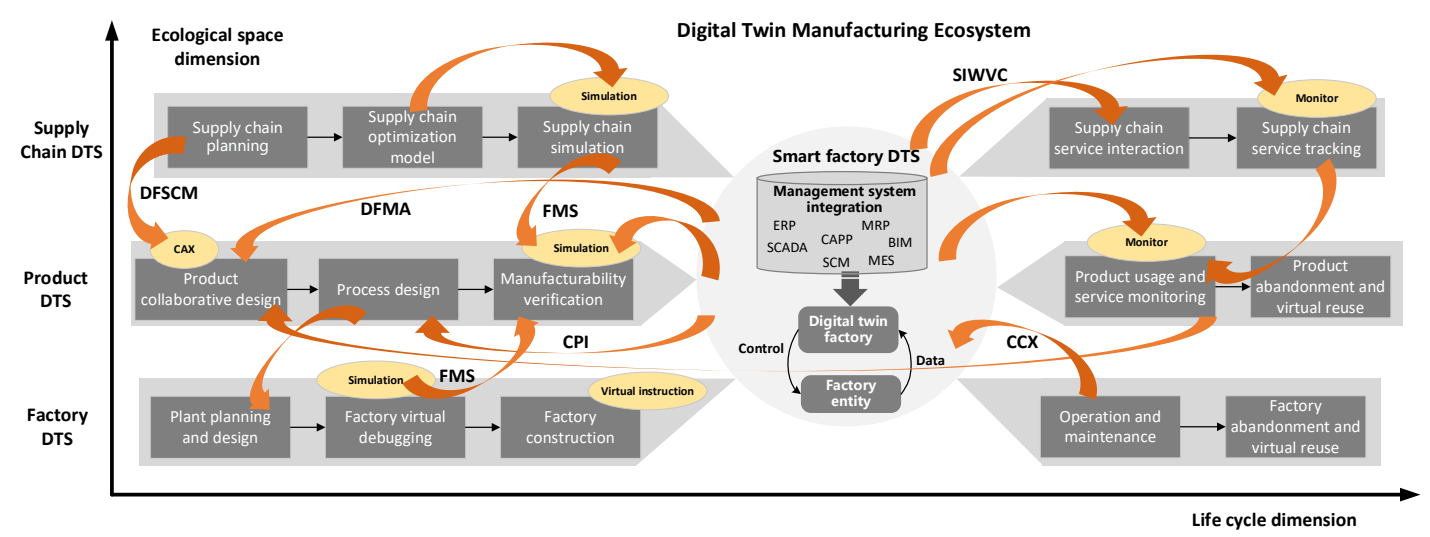

Figure 2 Digital twin manufacturing ecosystem

\subsection{The role of three dimensions of DTMEs in smart manufacturing}

\subsubsection{The factory lifecycle loop based on factory digital twin system}

The whole factory lifecycle is generally divided into factory planning and design stage, construction stage, operation and maintenance stage, and factory decommissioning and recycling stage. The factory has different goals at each stage of the factory lifecycle, and different requirements for information that has distinct characteristics. In the whole life cycle of the factory, the information generated by the factory is continuously accumulated and transmitted from the previous stage to the next stage, and the factory also needs to carry the integrated information of multi-fields, all elements and all business processes, which requires the digital technology for the factory lifecycle to meet the liquidity, integration and scalability requirements of the information flow.

Building information model (BIM) can effectively assist the information integration, interaction and collaboration in the field of construction engineering [26], which can effectively organize and track the information generated in the factory lifecycle, and ensure that the information is transferred to the next stage without "information loss" and "information inconsistency". The information models can be built according to the requirements and status of different stages of the factory in the BIM, i.e., from the factory planning and design, construction to operation and maintenance, the corresponding sub-information models are established for different service requirements. Each subinformation model has self-evolution and self-renewal mechanism. They can interact with the information models of the previous stage, and expand and integrate them to construct sub-models 
of this stage. According to this evolution mode, a complete information model oriented to the factory lifecycle is finally built.

The concept and technology of digital Twin are applied to the planning, design, construction, operation and maintenance of the factory, and the concept of factory digital embryo is firstly put forward. On the one hand, the factory digital embryo provides accurate three-dimensional models for BIM, and the digital documents related to the factory can be used as the basic data services of BIM. On the other hand, the factory is modeled during the design and planning stage of the factory. Therefore, the factory digital embryo was born before the physical factory. It is an ideal digital model that integrates production performance indicators, product process planning and scheduling models. The simulation of the manufacturing activities during the factory lifecycle is carried out by factory digital embryo to verify the feasibility and efficiency of the factory operation. In the factory construction stage, the physical factory is built by imitating the factory digital embryo which has been verified, which is a twin process from the factory virtual body to the physical entity. In the factory operation stage, the factory digital embryo is updated with information feedback from the physical factory, and enters the factory digital mapping body phase to interact with the physical factory. Therefore, the BIM-based factory digital twin system establishes sub-service models to meet the demands of different stages of the factory life cycle, and supports the storage, expansion and application of the factory entity information such as buildings and equipment in the smart factory, as shown in Figure 3.

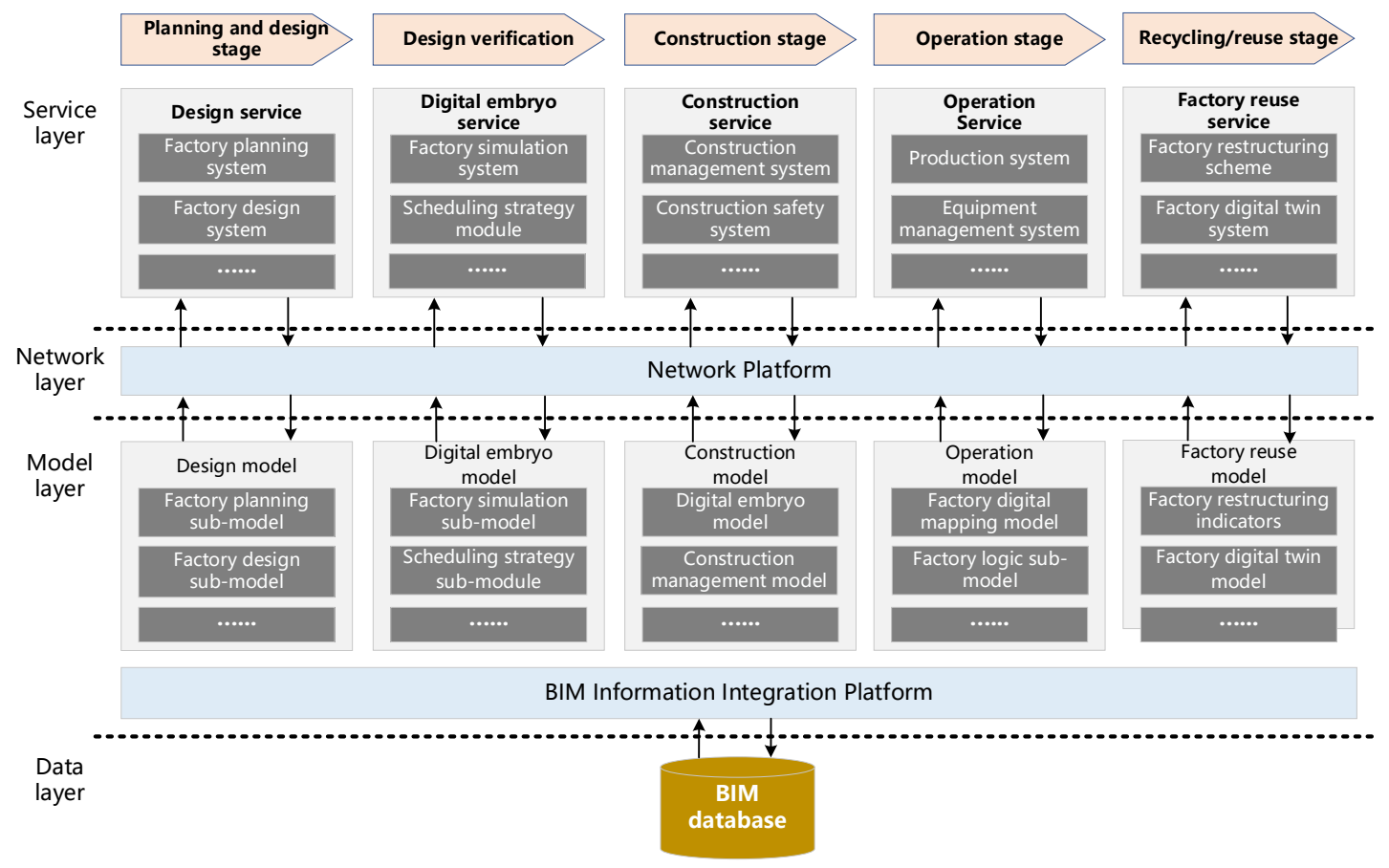

Figure 3 BIM-based information architecture of factory lifecycle

Starting from object-oriented thinking, the factory digital twin system is taken as the object. As shown in Figure 3, a factory digital twin with attributes and functions of all stages of the factory lifecycle is gradually constructed based on the factory digital embryo, and a formal modeling language [27] is used to configure and model the factory digital twin system, as follows: 


$$
\begin{gathered}
F D T S=\{F D T, P F\} \\
P F=\left\{F B, S P_{i}, S E_{j}, S G\right\} \\
F D T=\left\{B I M, F D T_{s t}, W S S M, S S E T_{\text {type }}, P S e t, I S e t\right\} \\
B I M=\{F D E m, F D M m, F T D m, F D D, F C D, I F C\} \\
W S S M=\{P P, P C, P T, O M\}
\end{gathered}
$$

Where FDTS represents the factory digital twin system; $P F$ is the physical factory, including the factory buildings, the $\mathrm{i}$-th smart product, the $\mathrm{j}$-th smart device and the smart gateway; FDT represents the factory digital twin; $F D T_{s t}$ is the state of the factory digital twin in its lifecycle; $S S E T_{\text {type }}$ is the service type in the factory digital twin system; PSet is the production dataset obtained from the physical factory; ISet is the instruction set of virtual production system to physical factory; BIM is an information management system for the whole factory lifecycle, including factory digital embryo model, factory digital mapping model, factory twin intelligent model, factory reconfiguration model, factory design planning documents, factory construction documents and factory building information standard system; WSSM represents the factory scheduling strategy models, including production process data, production constraints, production goals, and optimization algorithm models.

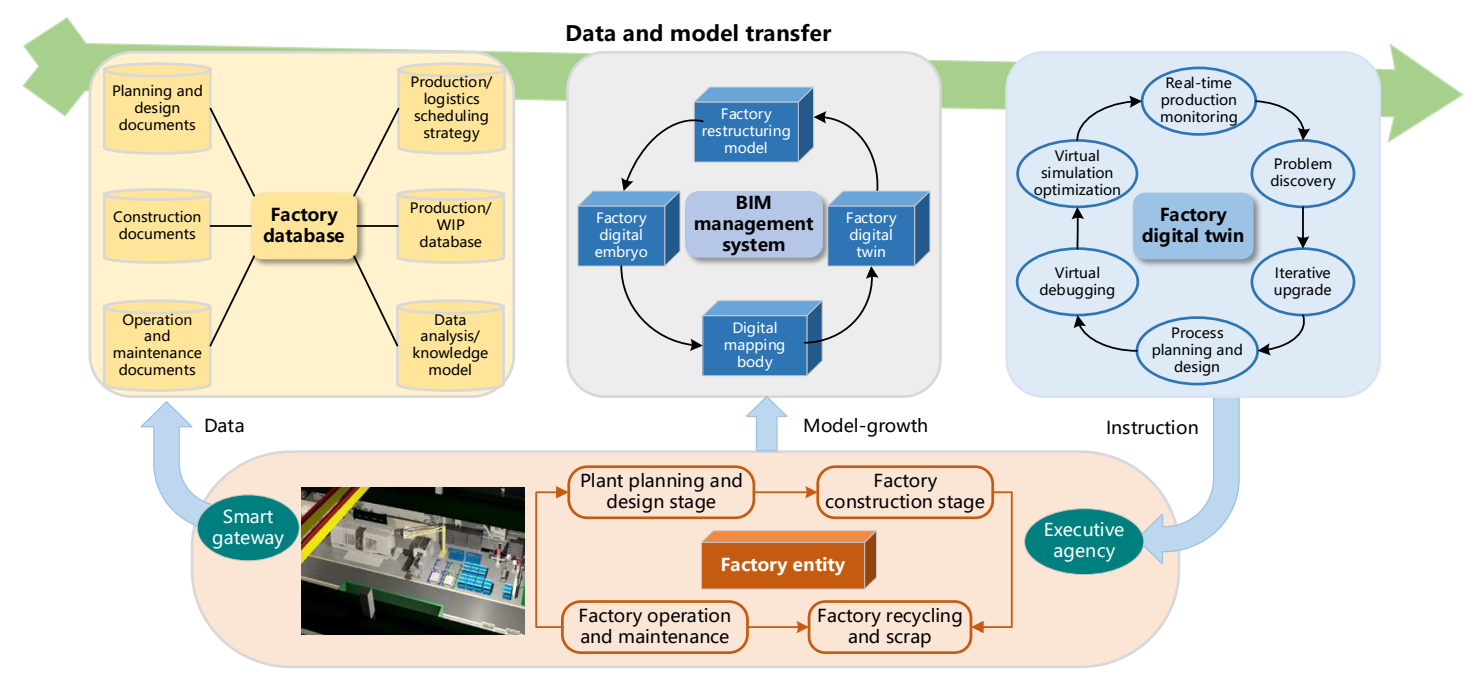

Figure 4 The factory digital twin system

From the configuration model of the factory digital twin system, it can be seen that the factory digital twin has different states throughout its lifecycle, and the different states interact dynamically, which can be described formally as:

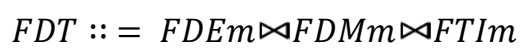

Where FDT represents the factory digital twin for the smart manufacturing of personalized products, FDEm is the factory digital embryo model, FDMm is the factory digital mapping body, FTIm is the factory twin intelligent model, and $\bowtie$ represents the connection and autonomous interaction among FDEm, FDMm and FTIm. It should be pointed out that FDEm, FDMm and FTIm are all dynamic models, and their geometric elements and states are constantly updated and evolved with the dynamic operation of the physical factory.

\subsubsection{The product lifecycle loop based on product digital twin system}

The evolution process of a physical product in its lifecycle is hierarchical, phased, interactive and 
coordinated. The product digital twin system is analyzed based on the concept of the digital twin lifecycle.

In the physical product design stage, first, it is necessary to fully understand the needs or wishes of users. The needs determine the structure, configuration, function, and minor differences of product, and the requirements given by customers are usually documents, and the product models in the design stage are virtual, and the requirements need to be mapped to the virtual models of the product in the virtual space. In the actual manufacturing scenario, the new generation of products will usually be iteratively improved based on the old generation of products according to the customer demands. As the previous generation of product digital twin whose life will not end, it has been iteratively optimized and accumulated a lot of information in the stages of $\mathrm{R} \& \mathrm{D}$, manufacturing, use and obsolescence, which will provide a reference model for the design and development of the new generation of products. As digital embryo that precedes the physical product, it is also the beginning and only model of product lifecycle data accumulation, integrating the product's three-dimensional geometric model, product related attribute information, process information, etc. Meanwhile, professional technicians are required to compile process flow based on experience summary and process knowledge, i.e., the product design models are transformed into manufacturing methods, steps and process parameters, and then the product digital embryo model and design documents are passed to the manufacturing stage. If the product directly enters the physical production system for production, the fault tolerance of product production is relatively low. Therefore, the initial production indicators system is established based on product requirements and process, and production scheduling strategies and logistics scheduling strategies are embedded in the factory digital embryo. As the prototype of the factory, the factory digital embryo can support collision and interference checking to find out the position conflicts between different devices, and implement the production simulation of the product. The accurate product size, assembly parameters and defective product information are fed back to the product design stage to optimize the product design and development. With the utilization of the feedback data in the use/maintenance stage, potential product design structural defects, performance defects and functional defects can be predicted to realize the initial product manufacturability simulation verification based on the SFDTS.

In the product manufacturing stage, the data (production progress, product quality, etc.) generated during the product manufacturing process are fed back to the product digital mapping body in real time to monitor the behavior and status of the product in real time, so as to realize the transparency of the product information in the manufacturing process. Finally, the instance product and the unique product model can be delivered to the customers. After the physical product is manufactured, the product digital mapping body as the only model has the same instance behavior as the physical product.

In the product operation and maintenance phase, all operation state changes and component change data of physical products, degradation information of product performance will be fed back to the product digital twin. When physical products at the service stage, some components of 
products are replaced due to the failure, wear or damage of components as the time goes by and the times of use increase. The product digital twin is always consistent with the physical product, and will automatically respond to the components change information of the product.

It can be seen that the product digital twin is the data center of the product lifecycle, and depicts all the information and models of the product from design, use to scrap / recovery stage. The product digital twin expresses the geometric characteristics, performance, status and functions of the product in an all-digital way, as the only basis for the product lifecycle information. Simultaneously, the product digital twin is also the information integration center of the entire value chain. Its main purpose is that the "value" in the entire value chain coordinates in time and space, which is not only the sharing of product information, but also service collaboration of the whole value chain based on the uniqueness of information and model. Therefore, the product information can be traced across the whole value chain, and can be fed back to the product digital twin in real time. Finally, the product digital twin with highly closed information loop will be formed. Figure 5 shows the process of high integration of virtual and real.

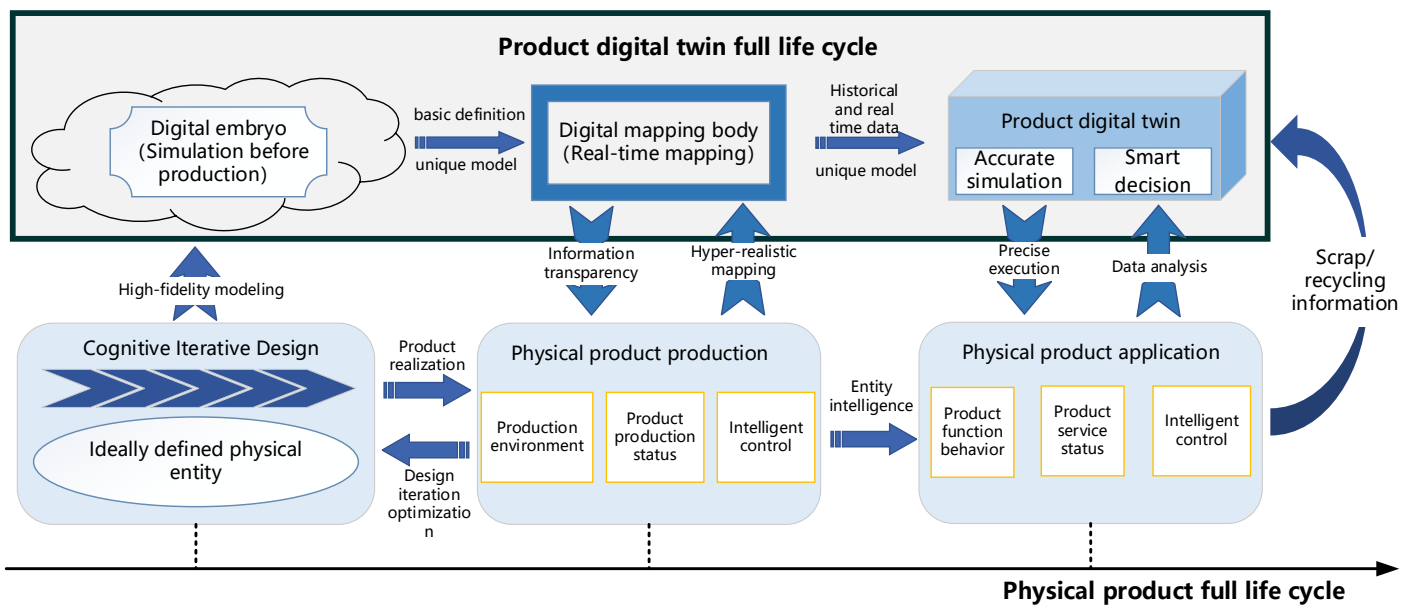

Figure 5 The evolution of the digital twin full life cycle

\subsubsection{The collaborative manufacturing loop based on supply chain DTS}

In the supply chain management cycle, all products in the supply chain will produce data related to their functions, performance and status. Using this aggregated massive data, enterprises can build the whole supply chain digital twin through modeling and simulation. Specifically, the geometric and business models of each node (storage, hub, transportation, distribution) in the supply chain are constructed. The nodes in the supply chain are the smallest structural components. Through modeling and simulating these structural organs, and connecting the models in series through open interfaces, the functions of the entire supply chain network can be operated in a virtual space. The essence of this process is to build a digital version of the supply chain, which not only provides information for the real-world supply chain, but also obtains information from the real-world supply chain for decision-making. At the same time, the supply chain digital twin not only reflects factual information about the history and current state of the supply chain, but can also provide future decisions and plans. It belongs to the "proactive" model. 
Supply chain DTS can realize service collaboration and service tracking management through real-time information visibility. Figure 6 shows the supply chain DTS based on the unique product model. In the digital twin collaborative interaction domain of supply chain DTS, the service evaluation model of the factory is established based on the factory digital twin and the comprehensive typical cases of the enterprises, and the partner selection strategy and collaborative optimization model are established by integrating the collaborative objectives and constraints of the factory, so as to realize the business collaboration at all levels of factory (workshop, production line, equipment) and upstream and downstream factories. When the information view of the downstream factory digital twin sends the service request, if the upstream factory can provide the corresponding services, the service view of downstream factory digital twin can invoke this service in the cooperative domain. Finally, the information view of the factory digital twin builds a visual management information model for the factory's dynamic supervision and evaluation mechanism. The downstream factory can periodically monitor, evaluate and manage the services provided by the upstream factory through a point-to-point visual service tracking method according to service needs.

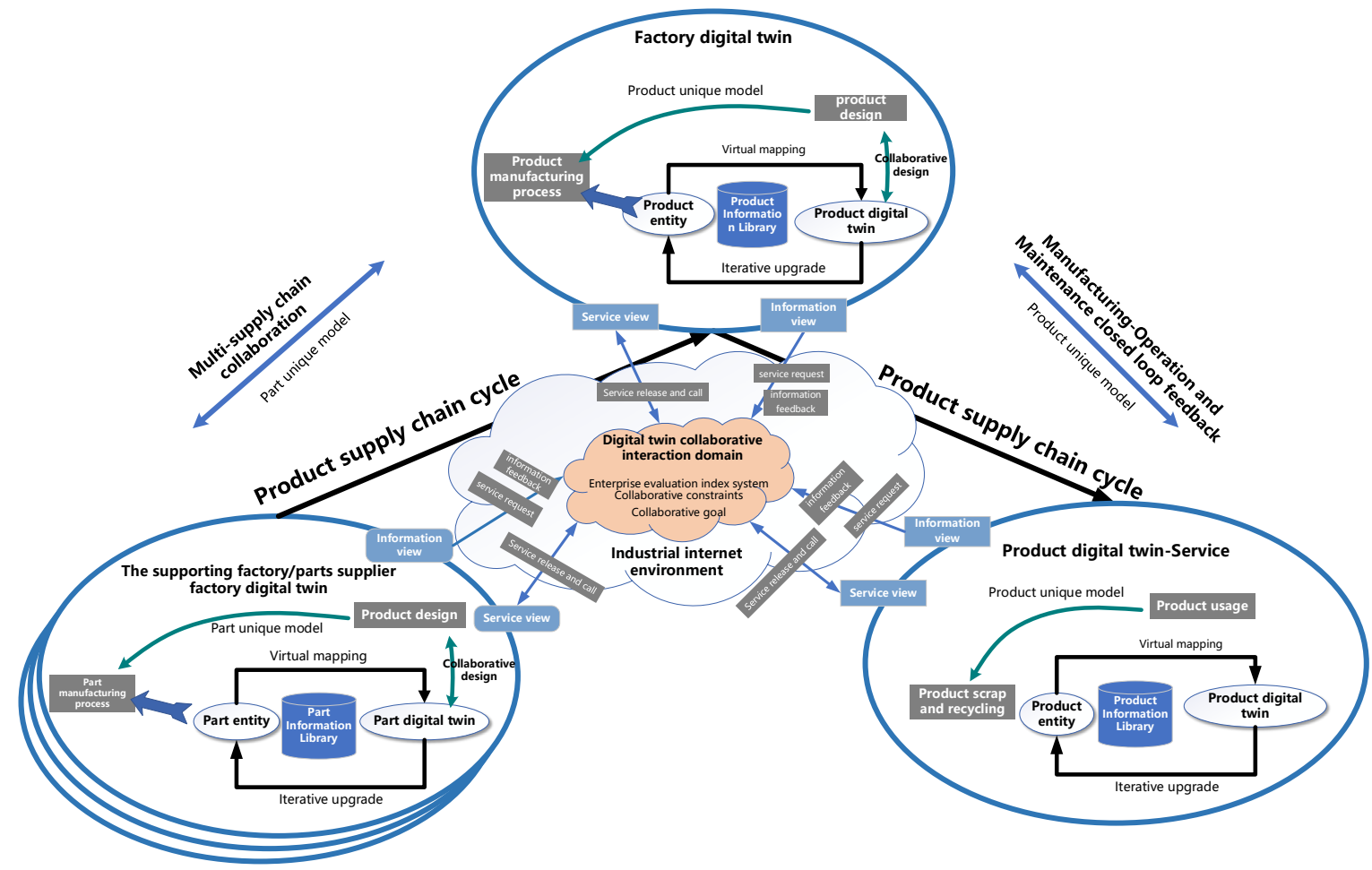

Figure 6 The supply chain DTS based on product unique model

\section{The implementation of SFDTS based on DTMEs}

\subsection{The characteristics and connotation of SFDTS}

\section{(1) Multi-domain DTS interaction}

In the digital twin manufacturing ecosystem, SFDTS is a system, in which factory DTS, product DTS, and supply chain DTS are integrated and interactive. The interaction among SFDTS, other three fields and their different stages can be realized through a virtual mapping space composed of resource flow, information flow, and service flow. Essentially, the seamless integration within each 
dimension and among the three dimensions of digital twin manufacturing ecosystem is the way to realize the capability of intelligent manufacturing system.

\section{(2) Data-knowledge hybrid drive service}

Knowledge service is a service that is integrated into users and runs through the users' decisionmaking process. SFDTS needs to provide the system's knowledge service to users in the most convenient and intuitive form, and directly interacts with users. The fully-perceived manufacturing data in the smart factory is the bridge between the production process and production decisionmaking. The production decision is driven by the analysis and statistics of big data, knowledge service modeling and visual logic modeling, which can effectively improve production management and control ability, production efficiency and product quality [28]. Therefore, it is necessary to propose the "physical resource-model-data-knowledge-service" multi-level mapping relationship and the data-knowledge hybrid drive service mechanism in the SFDTS to meet the market demands for mass customization services.

\section{(3) Service drive management}

The dynamic change of production tasks, the diversity of production / logistics objectives / constraints, the uneven set of production factors and the limitation of production capacity will reflect the complexity and instability of the manufacturing capacity of smart factory. Therefore, the SFDTS needs to create the smart services required in the manufacturing operation management process and further integrate services to meet the actual needs of intelligent production, precise management and control. SFDTS service integration and collaboration should form a hierarchical feedback relationship of "service dynamic scheduling mechanism $\rightarrow$ service matching and combination $\rightarrow$ service combination reliability evaluation". Meanwhile, smart factory is limited by production capacity, and needs to configure and interact with the manufacturing services provided by external manufacturing systems in the SFDTS.

\section{(4) Flexibility}

For large-scale customized services and fault disturbances, the resources, information and service in the SFDTS have dynamic evolution characteristics in the space-time continuum, and the services provided by the SFDTS are driven and matched by customer customized tasks. Therefore, in the whole product and factory lifecycle, with the virtual and real mapping and intelligent matching between the services provided by the SFDTS and customer needs, the resource flow and information flow in the SFDTS need to be adjusted quickly and efficiently, which causes the logical updating and upgrading of the production layout in the SFDTS. In the dynamic self-renewal and self-growth process of model, data and knowledge of SFDTS, its flexible characteristic is becoming more and more obvious.

\section{(5) Human-machine-material-information collaboration and integration}

CPS and digital twin technology are important enabling technologies for smart manufacturing systems. CPS aims to make perfect mapping and deep integration of cyber space and physical space to realize real-time simulation and smart management in the manufacturing process of personalized 
products [14]. In the smart factory for complex products, a completely unmanned manufacturing process is difficult to implement. Based on the new generation of optical perception technology, human can act as execution links that are difficult for machines in complex manufacturing environments. At the same time, compared to the derivative of the human brain-artificial intelligence, human perception and learning capabilities are more flexible and smarter. The humanperceived information, decision-making thinking, and execution capability play an indispensable role as the enhancement part of the smart factory. Eventually, the human-machine-thingsinformation synergy and integration in the smart factory will be realized. The framework of humancyber-physical (HCPS) is shown in Figure 7.

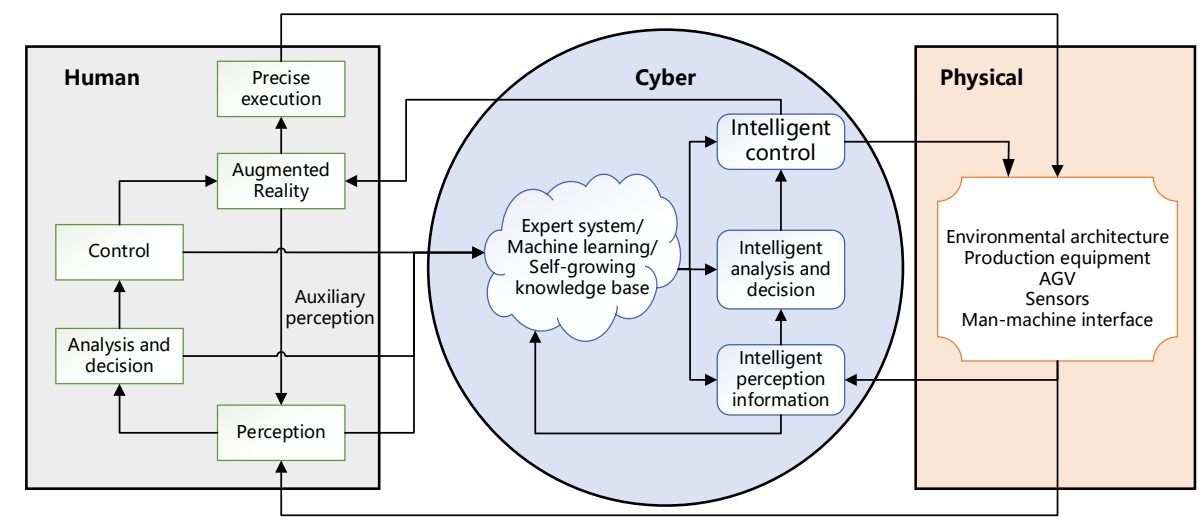

Figure 7 The framework of human-cyber-physical (HCPS)

\subsection{The Implementation architecture of SFDTS}

Based on the analytical results given, the construction process of the smart factory digital twin system is divided into three stages. Figure 8 shows the architecture and evolution process of the smart factory digital twin system.

Due to the increasing complexity of manufacturing systems and production equipment, designers lack an accurate understanding of the new manufacturing system, which may lead to design errors that will be corrected at a greater cost in future equipment installation and debugging. Traditional manual planning is basically ' extensive ' design method. After the completion of the new production system design, the specific equipment layout, trial production and production process are an uncertain paper scheme, which provides a lot of room for the construction suppliers. This will result in that the construction time and cost of the new factory cannot be well controlled. Therefore, in the first stage, SFDTS is needed for factory layout planning and preliminary production planning simulation. 


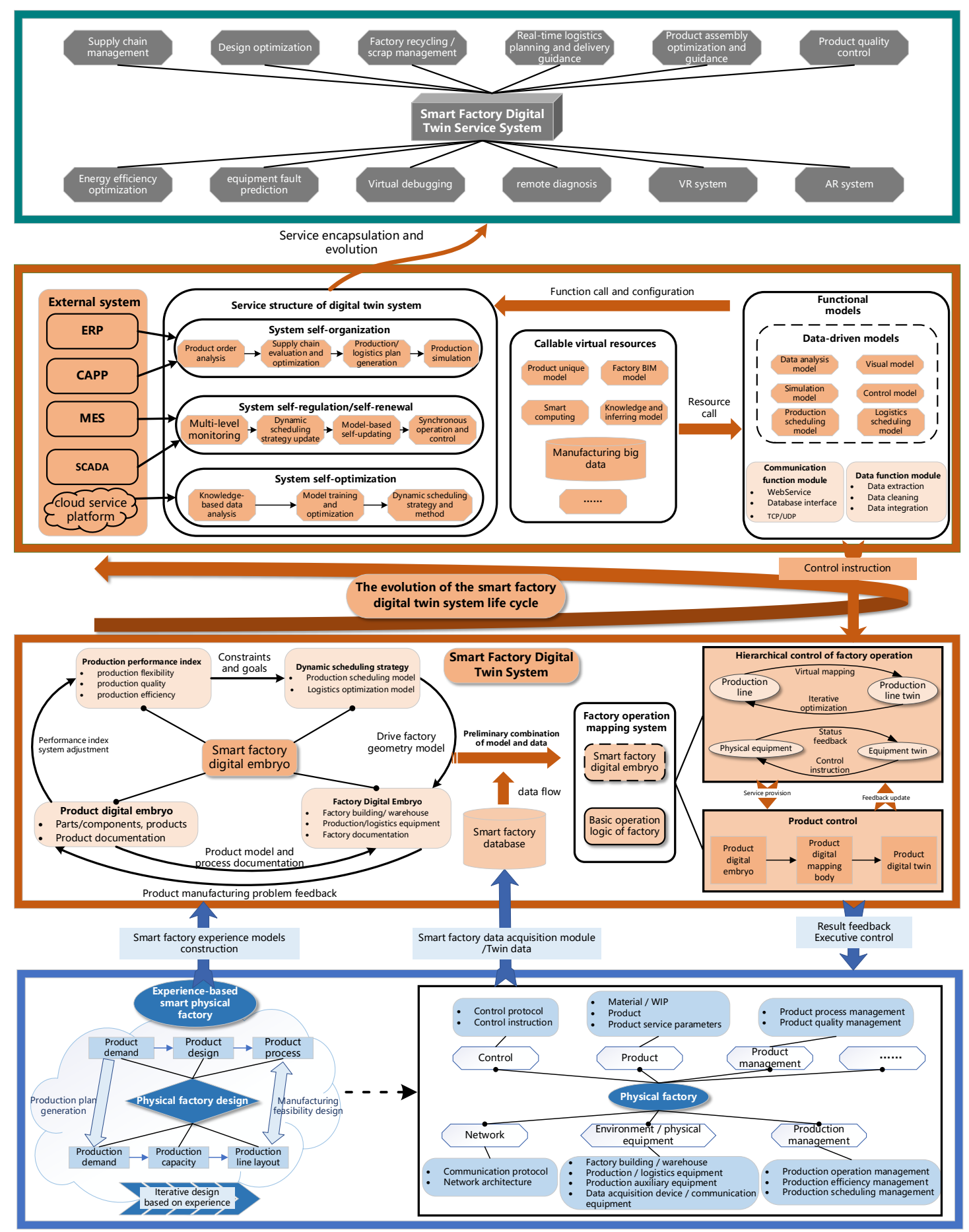

Figure 8 The implementation architecture of SFDTS

If we adopt the traditional factory layout method and use the simple computer-aided twodimensional graphic design, it will be difficult to obtain the optimal plan because we can't predict the unknown factors in advance and lack the analysis and comparison of various design schemes. Once the schemes need to be adjusted, the adjustment process will be very cumbersome. SFDTS uses object-oriented technology to build the basic resource database of the smart factory, and then three-dimensional visual simulation models of the production environment, machine tools, transportation equipment, warehouses, and buffers, etc. are built through visual modeling. Planners 
and operators can roam in the virtual space, adjust the spatial layout, implement the simulation of the dynamic production process, count the evaluation parameters, and determine the layout optimization plan.

In the early stage of SFDTS, planning analysis, auxiliary design and capability evaluation of factory logistics are also carried out. In the initial stage of plant planning, SFDTS organically combines the factory to be built with product production / logistics, realistically simulates the dynamic changes of production and logistics of manufacturing system on computer, analyzes the simulation data of production / logistics system by using system analysis method. It can also adjust the plant layout and improve the system capacity according to the results of production / logistics planning and design, so that the design and operation of production and logistics will become more reliable and effective, and the investment and cycle of factory planning will be greatly reduced.

The factory entity only exists after the completion of factory construction in the whole lifecycle. In the second stage, the main feature of SFDTS is the real-time hyper-realistic mapping from physical factory to virtual factory. The virtual models of the factory obtain high real-time data from the physical factory. After hyper-realistic modeling and statistical analysis, the virtual factory can simultaneously simulate and monitor the operating state of the physical factory. In the product manufacturing stage, the product status data and real-time production data are collected through sensors, and transmitted to the digital twin engine [29] in the digital twin system through the network of the production system for data processing, data storage and data analysis, so as to realize the realtime mapping between the production process in the physical factory and SFDTS. The operation analysis results of production data operation feedback to the production site in the way of information transparency, and actively guide the production activities of physical factory to change in the direction of the target.

In the third stage, the SFDTS is service-oriented to embed the intelligent algorithm models and construct a virtual-real fusion system with intelligent decision-making ability. At this time, the SFDTS is highly involved in the production activities of smart factory in the way of virtualization, intelligence and servitization of manufacturing resources and manufacturing capabilities, which makes the enterprise management system and execution system loosely coupled, and improves the flexibility, production efficiency and resource utilization of enterprise facing market demands.

In order to quickly respond to market demands and efficiently organize manufacturing resources, smart factory needs to form various manufacturing services and have the ability to manage manufacturing services, which include service resolution, function configuration and service tracking. Smart factory is the integration of multiple types of manufacturing resources, and the virtualized manufacturing resources have specific functions during the evolution of SFDTS. In the whole product value chain, there will be a variety of service requests between smart factories. Therefore, it is necessary to extract service requirements by referring to service interaction protocols and predefined service arrangement documents. SFDTS can organize and configure sub-functions in different ways according to different service requirements to form diversified manufacturing 
services. Then, the collection relationship of sub-functions is further described by defining service templates to provide services for manufacturing tasks. Meanwhile, knowledge model driven by mechanism and data can increase the intelligence of manufacturing services. On the one hand, the knowledge models come from the manufacturing knowledge, mechanism and even experience contained in key links of the production process and complex products; On the other hand, they come from the intelligent algorithm models constructed by processing and data mining analysis of workshop production and product data, including equipment fault diagnosis and prediction model, product quality evaluation model, etc. Therefore, knowledge-driven services can give users deeper understanding of the operating status and evolution of the physical factory [30].

The service architecture of SFDTS mainly includes three aspects: system self-organization, system self-regulation/self-renewal and system self-optimization. The system self-organization includes customer order demand analysis, supply chain evaluation optimization, production/logistics plan generation and production simulation. System self-regulation/selfoptimization includes multi-level monitoring of factory, dynamic scheduling strategy updating, model-based self-renewal. System self-optimization includes knowledge-based data analysis, model training and optimization, and dynamic scheduling strategies and methods. Then the services of SFDTS are released to the application terminal through service evolution and encapsulation, and interact with users most intuitively. The services include supply chain management, product assembly optimization and guidance, product quality control, real-time logistics planning and distribution guidance, and energy efficiency optimization, which participate in the management system of the factory and effectively and intelligently drives the factory management. The integration of information technology (such as AR and VR) and service can make the service sink to the production site, which enables people to conduct manufacturing activities more conveniently and accurately and realizes the collaboration and integration of human-machine-object-information in smart factory.

\section{Case Study}

In order to meet the high-variability and small-batch characteristics of market customer orders, a hydraulic cylinder factory is undergoing a smart upgrade and transformation. Due to the production mode of engineering to design (ETO) in the factory accounts for a considerable proportion in the production of hydraulic cylinders, it is difficult to implement some lean production criteria for standardized production, resulting in a large number of in-process inventory and prolonged delivery time, which is a major pain point in actual production. In the current production system, on-site realtime information perception is not accurate, and the production factors in the factory are not fully digitized, virtualized and transparent, resulting in the factory information flow cannot be effectively circulated in the upstream and downstream of the factory. Therefore, the flexibility of production and logistics in the factory is poor, which reduces the overall operating efficiency of the factory. In this paper, the intelligent upgrading of the hydraulic cylinder factory is taken as an example to 
implement the construction of the factory digital twin system from the three fields of factory, product and supply chain, including factory planning and reconstruction, factory production optimization, factory production operation monitoring and factory intelligent service; product processing simulation, product manufacturing process monitoring, in-process status tracking; supply chain service interaction and tracking. The implementation architecture is shown in Figure 9.

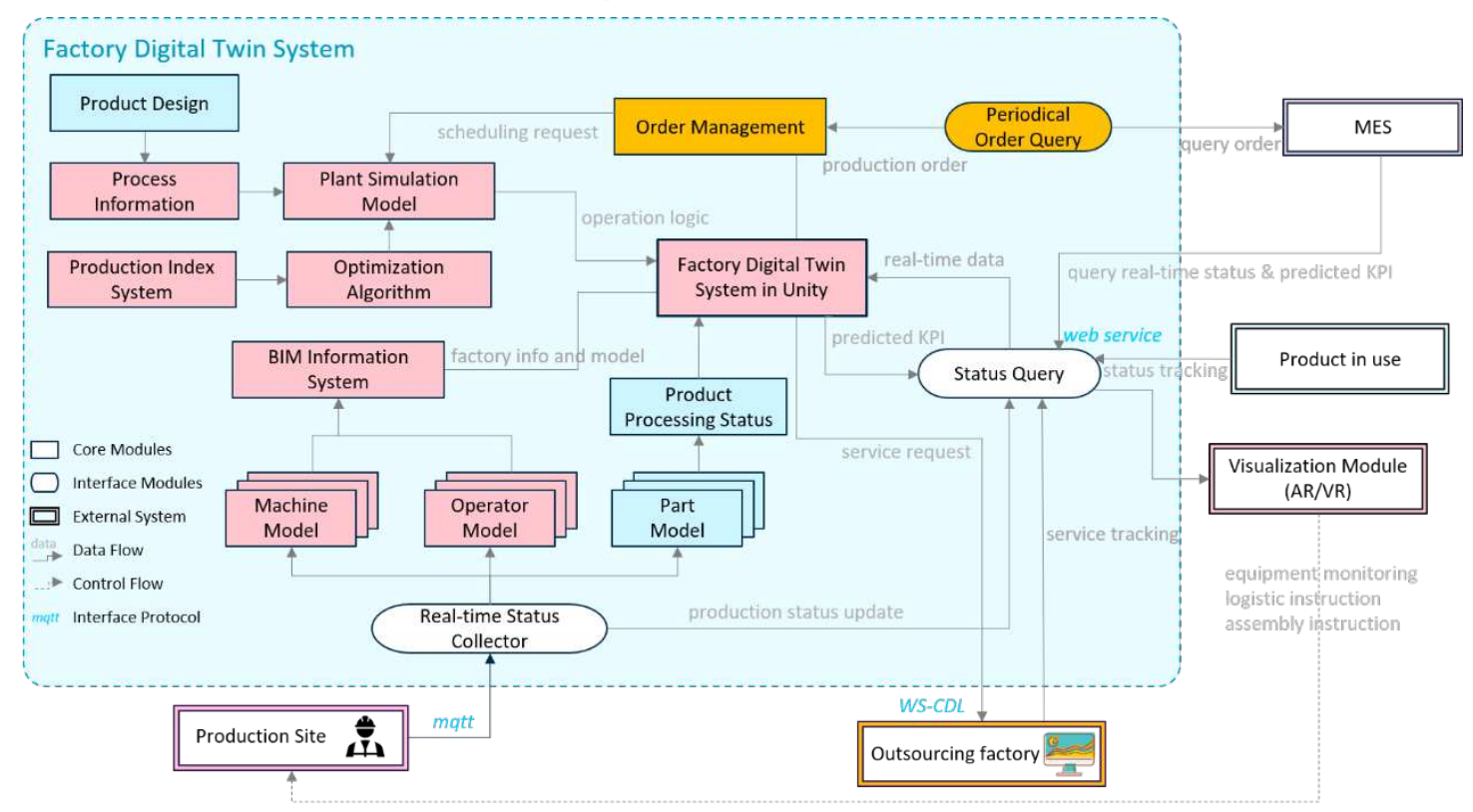

Figure 9 The implementation architecture of hydraulic cylinder factory digital twin system

\subsection{Plant Simulation-based factory reconstruction and production optimization}

Since the hydraulic cylinder factory is in the stage of intelligent upgrading, the factory has formed a complete set of process system and production optimization index system. Factory layout reconstruction and production logistics optimization are based on the process system and production optimization index system before intelligent upgrading. Plant Simulation is used to carry out twodimensional layout planning and production / logistics optimization simulation of the factory, and intelligent algorithms such as particle swarm optimization or genetic algorithm are embedded in the plant simulation model to generate production / logistics scheduling strategy. In the plant simulation model, the intelligent prediction model required for production / logistics scheduling and the factory layout planning based on optimization simulation can be obtained, and the analysis of production order processing time and equipment utilization data will be generated. The simulation results can guide the equipment layout planning of the production site and the production / logistics scheduling. Figure 10 shows the Plant Simulation model embedded with the production optimization index system and GA algorithm [31]. 


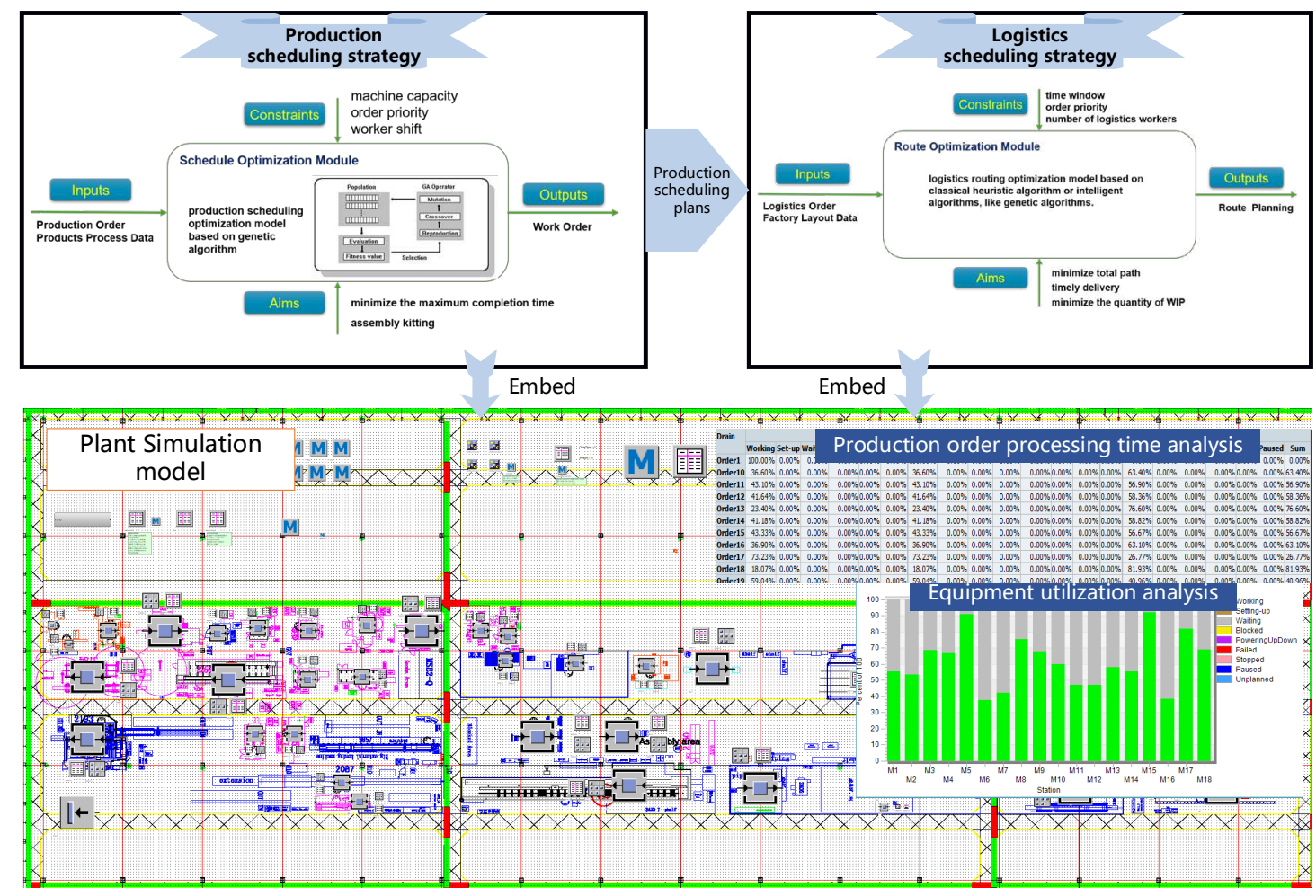

Figure 10 The plant simulation model of hydraulic cylinder factory

Aiming at the problem that there is a large number of in-process inventory in hydraulic cylinder factories and the delivery time is prolonged, the factory layout of reasonable production and operation can be planned based on the simulation analysis results of factory production / logistics scheduling.

However, the above-mentioned simulation model is only a simulation layout in a twodimensional scene, which does not achieve realistic or twin effects, nor can it effectively display factory buildings and equipment information. Therefore, it is necessary to build a three-dimensional 'archive' of the hydraulic cylinder factory. Based on the above two-dimensional factory layout, the BIM information system of the factory is needed to be constructed, including the composition structure of the factory, the tree management of the equipment models, the resource attributes and the attached building documents. The BIM information management system of hydraulic cylinder factory has been applied to the whole factory life cycle. The factory building and equipment information at each stage of the factory life cycle is recorded in the BIM information system and transmitted to the next stage of the factory lifecycle. Figure 11 shows the BIM information management system of hydraulic cylinder factory. 


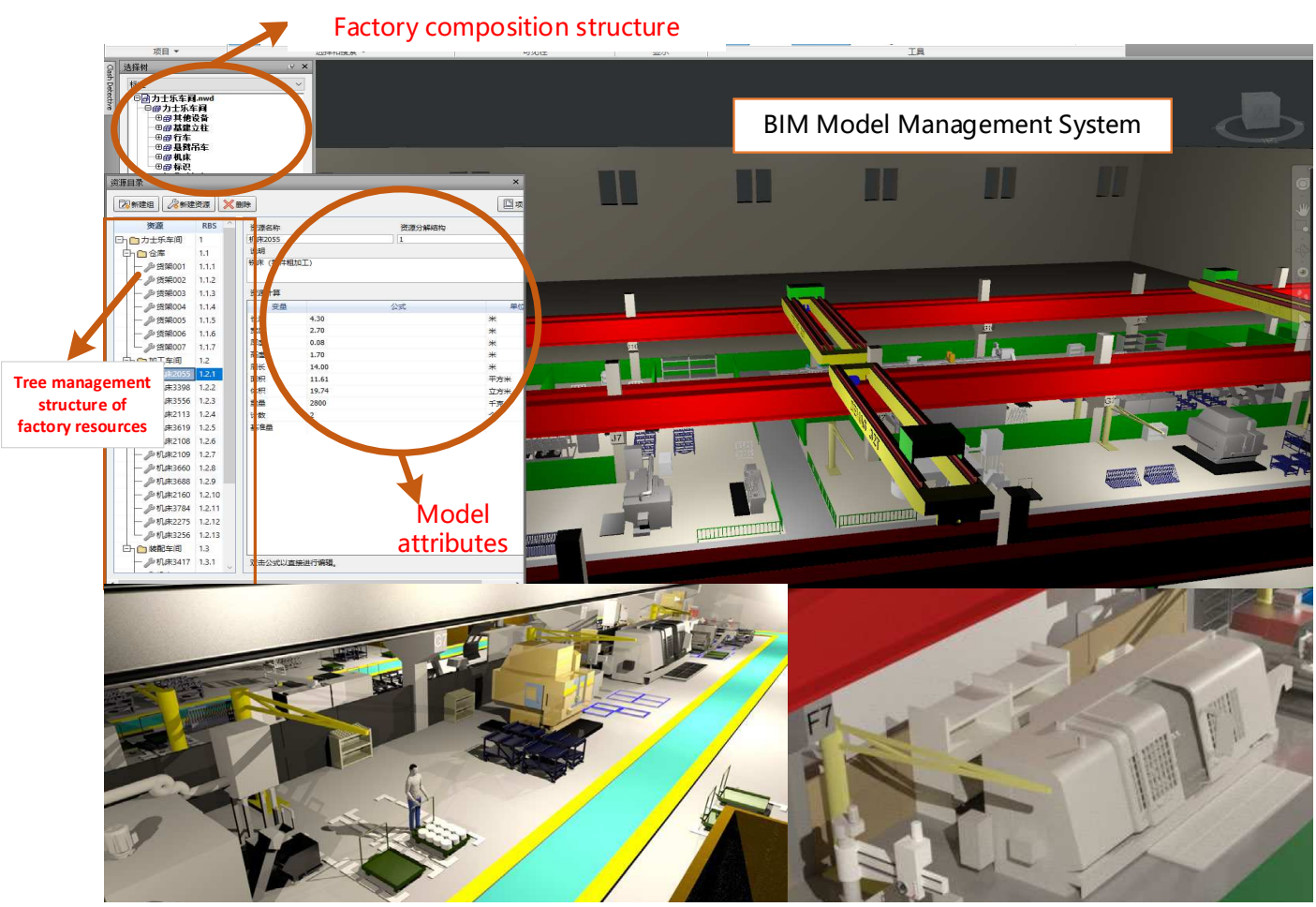

Figure 11 The BIM Information System of Hydraulic Factory

\subsection{Production process analysis of hydraulic cylinder factory}

After rational layout, the physical factory enters the next stage of the whole lifecycle of the factory, i.e., the factory operation stage. In this stage, production site information and in-process status information will be fed back to the digital mapping body of factory and products in real time.

The factory model of BIM information system will be imported into unity for secondary development. Unity is a cross platform 3D graphics rendering engine, which has convenient visual creation environment and powerful UI construction ability, and supports various script languages, including C \#, JavaScript [32]. Unity can obtain production process information by integrating various interfaces. Through the application of digital twin process simulation and big data analysis, the factory digital twin model and production process result analysis are shown in Figure 12. Figs. 12-1, 12-2 and 12-3 show the production progress of hydraulic cylinder product digital twin in the factory digital twin, which are the production simulation of the products before production in the factory DTS, the monitoring of the product manufacturing process and the status tracking of workin-process, including the tracking of the parts and components of the outsourcing service. In the product production process, the production process data, equipment data, product quality data, energy consumption, etc. collected by the intelligent collection equipment in the physical factory are used for data analysis, mining and cognitive decision-making to improve the management ability and production capacity of the factory. These functions correspond to different user groups, including enterprise management level users, workshop management control level users and equipment level users. Different users use different levels of system functions to jointly support the efficient and flexible operation of the factory. 


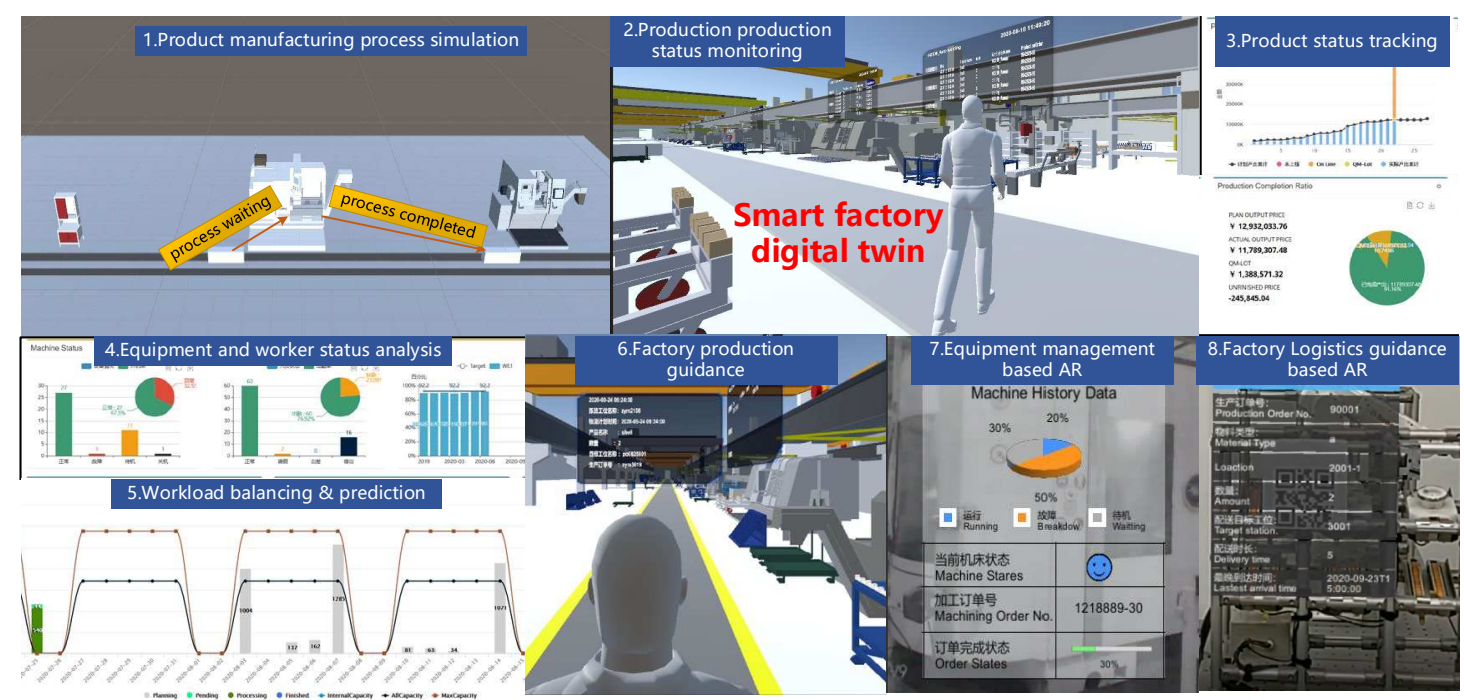

Figure 12 The manufacturing services based on factory digital twin system

The guidance information generated by production optimization simulation, production process analysis and other functions is integrated in the virtual space, and the services provided by the system for users at different levels of the factory need to be submerged into the factory site, i.e., the virtual information in the virtual space is used to guide the physical factory to change the manufacturing mode of the physical factory. Therefore, it is necessary to apply new information technology and build an information interaction channel between the virtual factory and the physical factory. For workshop-level managers, VR technology allows users to immersed in a complete virtual factory for physical factory production monitoring. For workshop production personnel, the information expansion and enhancement characteristic based on production scenarios of AR technology can make users understand the production site tasks naturally. Figure 12-5 shows the visual guidance of tasks for the logistics unit of a hydraulic cylinder factory based on VR; Figure 12-6 shows the equipment management based on AR, the management information includes: equipment history status, equipment current status, and order completion schedule, etc.; Figure 127 shows the on-site logistics guidance based on AR. AR equipment can acquire the logistics optimization results of Plant Simulation, and push the optimization results to the on-site logistics specialists based on each production scenario, which can assist on-site production and logistics execution, and improve workshop production efficiency .

\subsection{Service collaboration and tracking based on hydraulic cylinder factory supply chain DTS}

Multi-level and multi-granular services interact with each other within the hydraulic cylinder factory and between the factory and external suppliers. The information interaction interfaces of the collaborative interaction domain of the factory supply chain DTS in Figure 6 are used, and the basic service interaction rules are designed to realize the interaction strategy of factory manufacturing services. Then, the manufacturing service arrangement documents are formed based on the WSCDL standard, and information is exchanged according to the service arrangement document during service execution, and service tracking management is completed.

The parts processing method of the hydraulic cylinder factory can be summarized in the following 
three steps: blank processing, rough machining, and finish machining. Both existing manufacturing service providers A and B can complete the manufacturing tasks of the above steps, i.e., they can provide each type of manufacturing service or the corresponding combination of services. In order to effectively coordinate the processing and manufacturing processes of each sub-order and each service provider, different service providers need to exchange order information with upstream and downstream service providers and demanders according to each order arrangement information. Taking a sub-order order_ 2 as an example, the service interaction collaborative simulation of each service provider is shown in Figure 13. The total order completion time is $52 \mathrm{~h}$ and the processing time, exception handling time, order switching time, and waiting (idle) time data of each service provider are shown as the pie charts in figure 13.

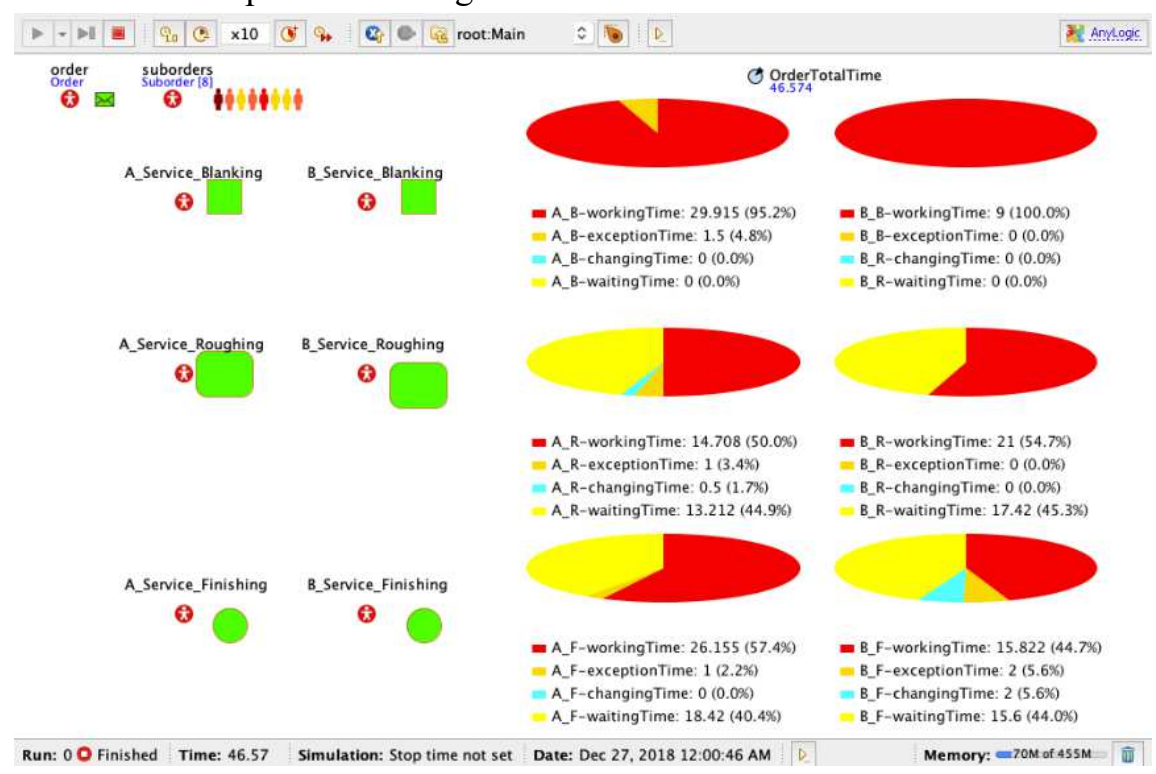

Figure 13 Simulation of Service Interaction Collaboration among Service Providers

In the service interaction and collaboration mode, the upstream service providers can not only actively send order exception information to the downstream service demanders, but also the downstream service demanders can actively obtain order status and progress from the upstream service providers. According to their own service execution strategy, they can delete abnormal services or update their production orders at any time. As shown in table 1, a comparison of the scheduled production orders and actual production orders for finish machining service of service demander A.

Table 1 Comparison of finishing service order execution orders of service demander A

\begin{tabular}{ccc}
\hline $\begin{array}{c}\text { Whether to consider the } \\
\text { abnormal factors }\end{array}$ & Scheduled production sequence & Actual production sequence \\
\hline No & order_3 $\rightarrow$ order_5 & order_3 $\rightarrow$ order_6 \\
& $\rightarrow$ order_6 $\rightarrow$ order_8 & $\rightarrow$ order_5 $\rightarrow$ order_8 \\
Yes & order_3 $\rightarrow$ order_5 & order_3 $\rightarrow$ order_6 \\
& $\rightarrow$ order_6 $\rightarrow$ order_8 & $\rightarrow$ order_5 $\rightarrow$ order 8 \\
\hline
\end{tabular}




\subsection{Comparison results}

In order to verify the feasibility and effectiveness of the SFDTS based on DTMEs in the hydraulic cylinder factory, the operating profit parameters of the factory before and after the operation of the SFDTS were collected. Table 2 shows the experimental comparison before and after the operation of the factory's digital twin system. The first-pass yield has increased by $13.6 \%$; the standard workin-process inventory (WIP) has decreased by 124 on average; the delivery date has been advanced by 13 days on average; the equipment utilization rate has increased by $5 \%$ and became more balanced; the product defect rate has been reduced by $3.2 \%$.

Table 2 The experimental results of the SFDTS operation

\begin{tabular}{lll}
\hline Indicators & Without SFDTS & SFDTS \\
\hline First-pass yield & $81.3 \%$ & $94.9 \%$ \\
WIP & 332 & 208 \\
Delivery date & 10 days delayed & 3 days in advance \\
Equipment utilization & $83 \%$ & $88 \%$ \\
Defective rate of products & $6.7 \%$ & $3.5 \%$ \\
\hline
\end{tabular}

6 Conclusion and future work

With the implementation of the smart manufacturing strategy, digital twin technology is increasingly being applied to all levels of the manufacturing industry. The core concept of digital twin technology is the integration of virtual and real spaces, which provides a new method and idea for the development of current manufacturing industry. This paper first introduces the concept of digital twin, and analyzes its connotation and the necessity of establishing digital twin manufacturing ecosystem from the perspective of product manufacturing process demands. Furthermore, the role of digital twin system in all dimensions of the digital twin manufacturing ecosystem is studied. Based on the requirements of digital twin manufacturing ecosystem, the composition, evolution law and mutual integration relationship of SFDTS are designed and analyzed. Finally, the application case shows the construction process, components and service application scenarios of SFDTS, and proves that it can effectively reduce the work-in-process inventory and advance their delivery time.

At present, this research is in its infancy and still requires a lot of work. Future research work on this topic needs to be undertaken as follows: (1) The data and models of virtual space in digital twin system come from physical space, and the effective expression of virtual elements depends on the quality and fusion degree of data and models. It is necessary to explore the quality and fusion mechanism of twin data and models in virtual space. Further research is needed on the twin quality evaluation system and fusion quality standard of data sets and model sets of the whole business process. (2)At present, the data and models obtained from the physical factory have not been fully and intelligently applied. It is necessary to further explore the full integration and application of intelligent algorithms and the twin data/models in the virtual space. We can further study the reasonable integration of other fields with digital twin system, such as computer vision, and expand the business scope of digital twin system for smart manufacturing. 
Author contributions Luyao Xia: writing-original draft and methodology. Jianfeng Lu: writing-review and methodology. Hao Zhang: conceptualization. Mengying Xu: validation and supervision. Sheng Wang: formal analysis. Zhaojia Li: investigation.

Funding The Major Program of National Natural Science Foundation of China under Grant No. 71690230/71690234; National Key R\&D Program of China under Grant No. 2017YFE0100900; Shanghai "science and technology innovation action plan" (No. 19DZ1206800).

Data availability The data used to support the findings of this study are included within the article.

\section{Compliance with ethical standards}

Competing interests The authors declare that they have no competing interests.

Ethical approval Not applicable.

Consent to participate Not applicable.

Consent to publish Not applicable 


\section{Reference}

[1] Li K, Zhou T, and Liu BH (2020) Internet-based intelligent and sustainable manufacturing: developments and challenges. Int J Adv Manuf Technol 108:1767-1791. https://doi.org/10.1007/s00170-020-05445-0

[2] Bao J, Guo D, Li J, Zhang J (2019) The modelling and operations for the digital twin in the context of manufacturing. Enterprise Information Systems 13(4):534-556. https://doi.org/10.1080/17517575.2018.1526324

[3] Ding K, Zhang XD, Zhou GH et al (2019) Digital twin-based multi-dimensional and multi-scale modeling of smart manufacturing spaces. Comput Integr Manuf Syst 25(06):1491-1504

[4] Chryssolouris G, Mavrikios D, Papakostas N et al (2009) Digital manufacturing: History, perspectives, and outlook. Proc Inst Mech Eng Part B 223(5):451-62

[5] Li BH, Zhang L, Wang SL, Tao F, Cao JW, Jiang XD, Song X, Chai XD (2010) Cloud manufacturing: a new service-oriented networked manufacturing model. Comput Integr Manuf syst 16(1):1-7

[6] Chen T and Tsai HR (2017) Ubiquitous manufacturing: Current practices, challenges, and opportunities. Robotics and Computer-Integrated Manufacturing 45:126-132. https://doi.org/10.1016/j.rcim.2016.01.001

[7] Yao XF, Lian ZT, Yang Q et al (2014) Wisdom manufacturing: new humans-computers-things collaborative manufacturing model. Comput Integr Manuf syst 20(6):1490-1498

[8] Li PG (2019) Smart manufacturing must consolidate the foundation of "data" and "interconnection". Wisdom China (07):52-53

[9] Zhang Y, Feng YP, Rong G (2016) Reference model and key technologies of smart factory. Comput Integr Manuf syst 22(01):1-12

[10] Tao F, Zhang M (2017) Digital Twin Shop-Floor: A New Shop-Floor Paradigm Towards Smart Manufacturing. IEEE Access doi:https://doi.org/10.1109/ACCESS.2017.2756069

[11] Tao F, Zhang H, Liu A et al (2019) Digital Twin in Industry: State-of-the-Art. IEEE Transactions on Industrial Informatics 15(4):2405-2415. https://doi.org/10.1109/TII.2018.2873186

[12] Tao F, Cheng Y, Cheng JF, et al (2017) Theories and technologies for cyber-physical fusion in digital twin shop-floor. Comput Integr Manuf syst 23(8):1603-1611

[13] Guo DS, Bao JS, Shi GW et al (2018) Research on modeling of aerospace structural parts manufacturing workshop based on digital twin. Journal of Donghua University (Natural Science) 44(04):578-585

[14] Zhao H, Zhao N, ZHANG SP (2019) Factory design approach based on value stream mapping and digital twin. Comput Integr Manuf syst 25(06):1481-1490

[15] Park KT, Lee J, Kim HJ et al (2020) Digital twin-based cyber physical production system architectural framework for personalized production. Int J Adv Manuf Technol 106:1787-18 10. https://doi.org/10.1007/s00170-019-04653-7 
[16] Park KT, Nam YW, Lee HS et al (2019) Design and implementation of a digital twin ap plication for a connected micro smart factory. Int J Comput Integr Manuf 32(6):596-614. ht tps://doi.org/10.1080/0951192X.2019.1599439

[17] Tao J, Dai YC, Wei R (2017) Study on production lifecycle Based on digital thread and digital twin. Aeronautical Manufacturing Technology (21):26-31

[18] Miao T, Zhang X, Xiong H et al (2019) Application and expectation of digital twin in product lifecycle. Comput Integr Manuf syst 25(06):1546-1558

[19] Grieves M (2005) Product lifecycle management: the new paradigm for enterprises. Int J Prod Dev 2(1/2):71-84

[20] Grieves M (2014) Digital twin: manufacturing excellence through virtual factory replication. www.apriso.com/library/Whitepaper_Dr_Grieves_DigitalTwin_ManufacturingExcellence.php

[21] Zhuang CB, Liu JH, Xiong H (2018) Digital twin-based smart production management and control framework for the complex product assembly shop-floor. Int J Adv Manuf Technol 96:1149-1163. https://doi.org/10.1007/s00170-018-1617-6

[22] Negri E, Fumagalli L, Macchi M (2017) A Review of the Roles of Digital Twin in CPS -based Production Systems. Procedia Manufacturing 11:939-948. https://doi.org/10.1016/j.pro mfg.2017.07.198

[23] Rosen R, Von WG, Lo G, Bettenhausen KD (2015) About the Importance of Autonomy and Digital Twins for the Future of Manufacturing. IFAC-PapersOnLine 48:567-572. https://doi.org/10.1016/j.ifacol.2015.06.141

[24] Al-Sayed R, Yang J (2018) Towards Chinese smart manufacturing ecosystem in the context of the one belt one road initiative. Journal of Science and Technology Policy Management 11:291-310. https://doi.org/10.1108/JSTPM-02-2018-0012

[25] Li J, Tao F, Cheng Y, Zhao L (2015) Big Data in product lifecycle management. Int J Adv Manuf Technol 81:667-684. https://doi.org/10.1007/s00170-015-7151-x

[26] Vanlande R, Nicolle C, Cruz C (2008) IFC and building lifecycle management. Automation in Construction 18(1):70-78

[27] Ma J, Chen H, Zhang Y et al (2020) A digital twin-driven production management system for production workshop. Int J Adv Manuf Technol 110:1385-1397. https://doi.org/10.1007/s00170020-05977-5

[28] Lee J, Lapira E, Bagheri B, Kao H (2013) Recent advances and trends in predictive manufacturing systems in big data environment. Manufacturing Letters 1:38-41. https://doi.org/10.1016/j.mfglet.2013.09.005

[29] Xia L, Lu J, Zhang H (2020) Research on Construction Method of Digital Twin Workshop Based on Digital Twin Engine. 2020 IEEE International Conference on Advances in Electrical Engineering and Computer Applications 417-421. https://doi.org/10.1109/AEECA49918.2020.9213649

[30] Chen G, Wang P, Feng B, Li Y, Liu D (2020) The framework design of smart factory in discrete 
manufacturing industry based on cyber-physical system. Int J Comput Integr Manuf 33:79-101. https://doi.org/10.1080/0951192X.2019.1699254

[31] Gong GL, Deng QW, Gong XR et al (2018) A new double flexible job-shop scheduling problem integrating processing time, green production, and human factor indicators. Journal of Cleaner Production 174:560-576

[32] Zhang LL, Li RY, Li XJ et al (2014) Research on Communication Method between Unity3D and Database. Computer Technology and Development 24(3):229-232 